
DOI: https://doi.org/10.37359/JOPE.V33(4)2021.1214

\begin{abstract}
المستخلص
هدف البحث الى تصميم وبناء وتقتين اختبار قطع ونتنتيت الكرة بين اربعة لاعبي هجوم للاعبي اندية دوري الدرجة الممتازة بكرة اليد. واستخذم الباحثان المنهج الوصفي بالأسلوب المسحي وذللك لملاعمته لحل مشكلة البحث وتحقيق اهدافه، تكوَّن

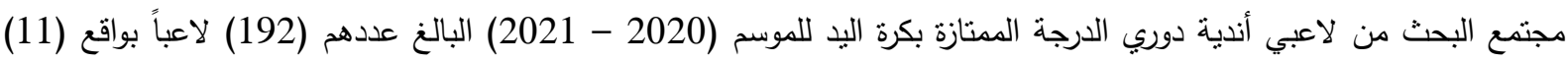
نادي يمثلون الأندية المشاركة بالدوري العراقي، ونم استبعاد جميع حراس المرمى فبلغ عدد اللاعبين فقط (159) لاعباً وهم يمنلون مجتمع البحث، أما عينة البحث فقد اختار الباحثان (103) لاعباً منهم، حيث بلغت النسبة المئوية (64.78\%) من مجتمع البحث،

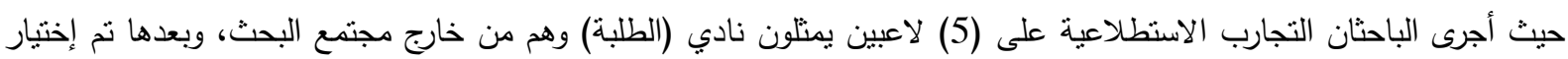

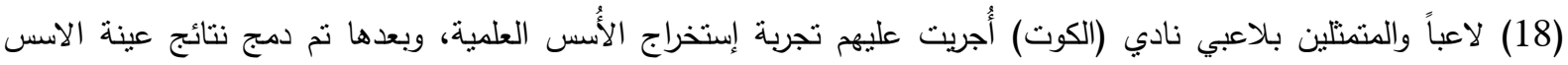
العلمية مع (20) لاعباً ليصبحوا (38) لاعباً أُجريت عليهم تجربة البناء، اما عينة التقنين فقد قام الباحث بإجراء الاختبارات من خلال تطبيقها على عينة التقنين والتي تكونت من (65) لاعباً، واستخراج الدرجات والمسنويات المعيارية لها، واستتنج الباحثان بأن اختبار قطع وتتنيت الكرة بين اربعة لاعبي هجوم يعد محكاً موضوعياً لكونها أكثر واقعية عند عملية التقويم للعبة كرة اليد، وتسهم في لائه الارتقاء بمستويات المهارات الدفاعية بكرة اليد موضوعة البحث، ويوصي الباحثان باعتماد اختبار قطع وتتنتيت الكرة بين اربعة لاعبي لئي

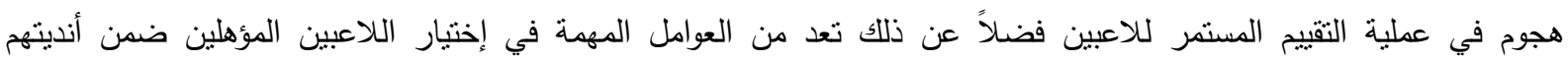

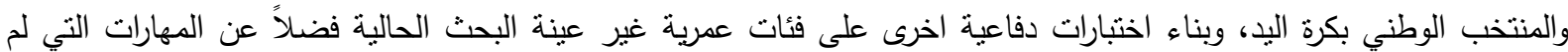
تبحث، وكذلك إلاهتمام بتدريب المهارات الدفاعية. الكلمات المفتاحية: بناء وتقنين الاختبارات، قطع وتتشتيت الكرة، كرة اليد، الاختبار والقياس.
\end{abstract}

\title{
ABSTRACT \\ Constructing and standardizing Interception and Passing Among four Attackers in Handball Primer League Players
}

The researchers aimed at designing and constructing, and standardizing a test for interception and passing among four attackers for primer league handball players. The researchers used the descriptive method on (103) primer handball league players of the season 2020 - 2021 from 11 clubs participating in the primer league. A pilot study was conducted on (5) players from (Al Talaba club) then (18) players from Al Koot club were selected for experimental bases, other formed standardizing subjects. The researchers concluded that the test is objective and they recommend using this test for evaluating players as well as for payers' selection within clubs and international teams of handball. They finally recommended using these tests on other age groups and skills.

Keywords: constructing tests, standardization of tests, handball, tests and measurement.

(1) طالب دراسات علبي (الدكتوراه)، جامعة بغداد، كلبة التربية البننبة وعلوم الرياضة. (saadalm@gmail.com) Saad Dari Hamel, Post Graduate Student (PH.D), University of Baghdad, College of Physical Education and Sport Sciences, (saadalm@gmail.com) (+9647713269700).

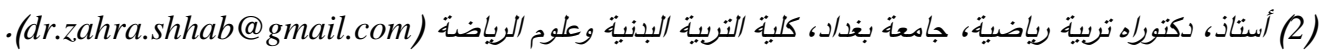
Zahra Shehab Ahmed, Prof (PH.D), University of Baghdad, College of Physical Education and Sport Sciences, (dr.zahra.shhab@gmail.com) (+9647712094018). 
تعـد الاختبـارات والقيـاس مـن الوسـائل العلميـة الضـرورية فـي مجـال التربيـة الرياضـية لمـا لهـا اهميـة فـي

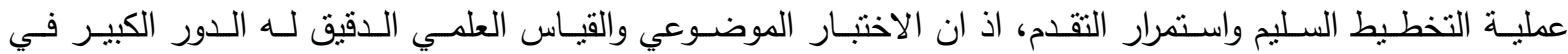

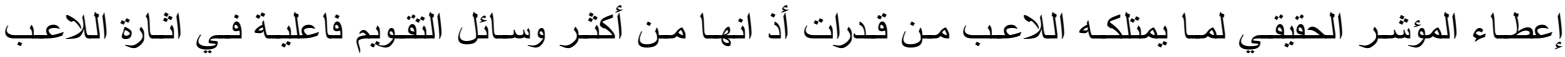

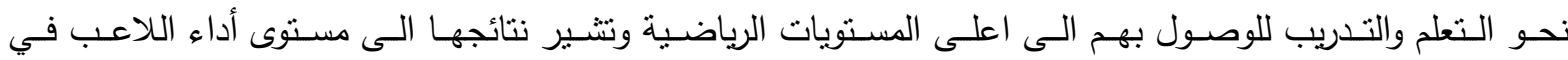

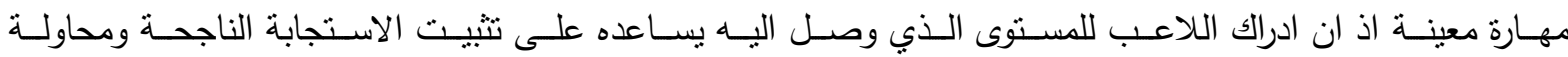
اصلاح المحاولات الخاطئة وتجنبها.

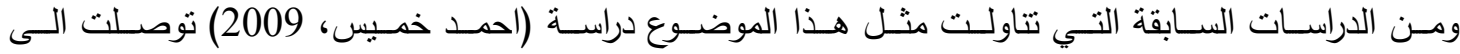

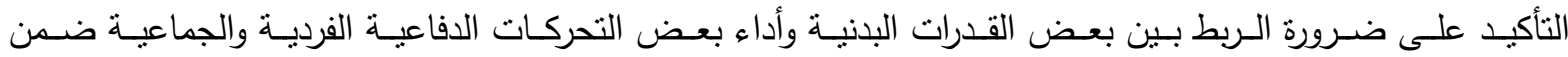

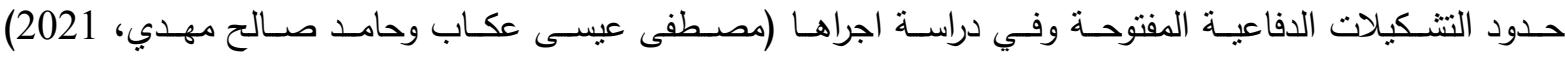

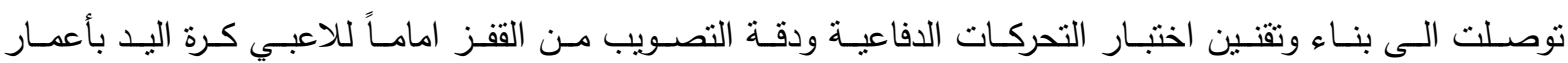

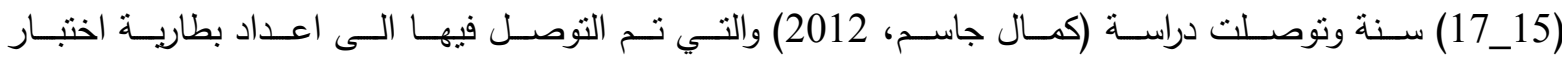

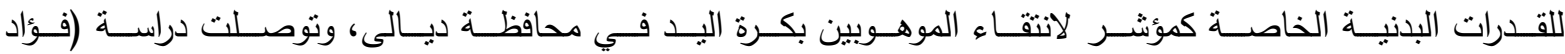

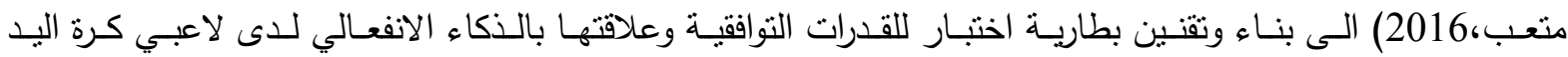

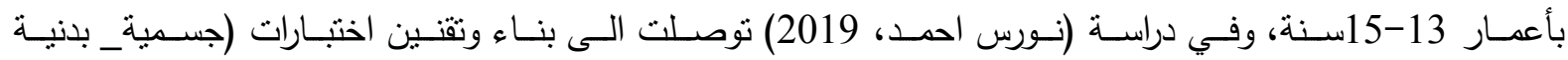

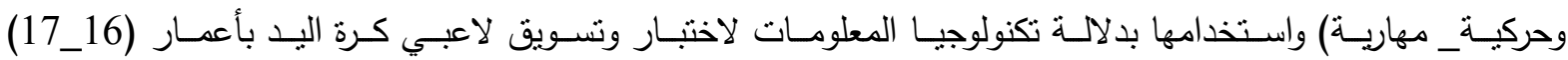
سنة.

وممـا تقدم تظهر أهميـة البحـث في تصـميم وبنـاء وتقنين اختبـار قطـع وتتـتيت الكـرة بـين اربعـة لاعبـي

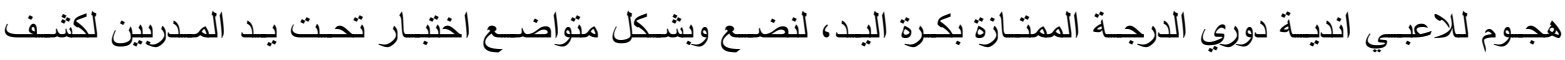

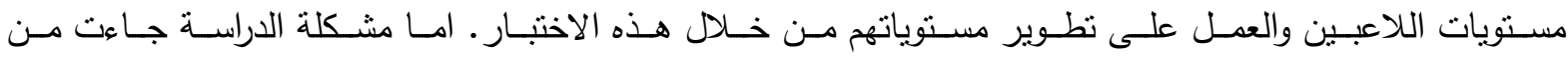

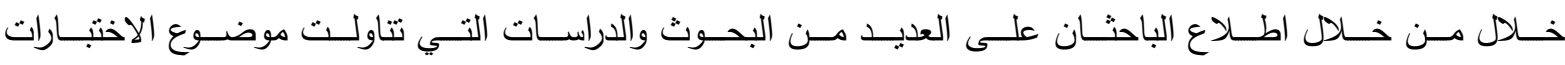

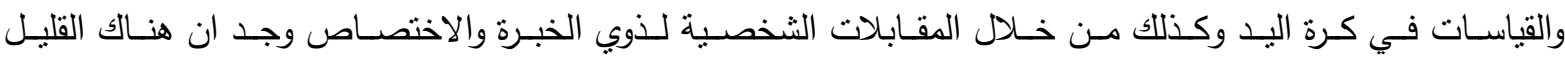

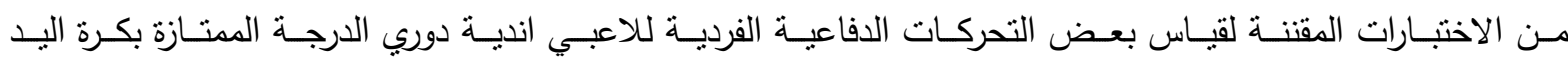

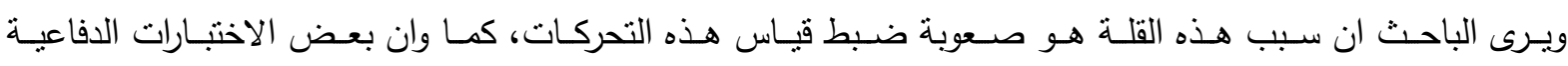

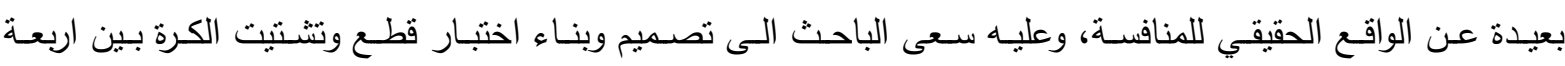

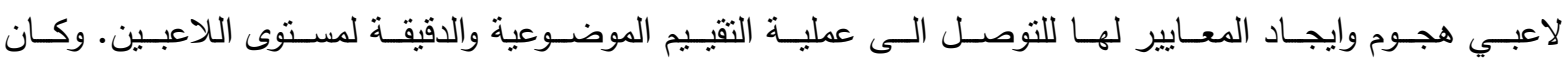

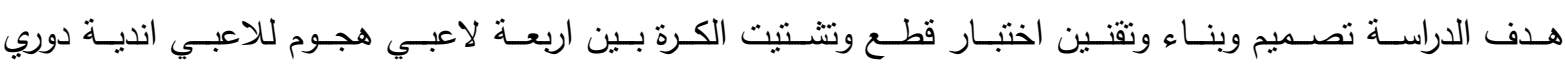
الدرجة المثتازة بكرة البد.

\section{الطريقة والأدوات:}

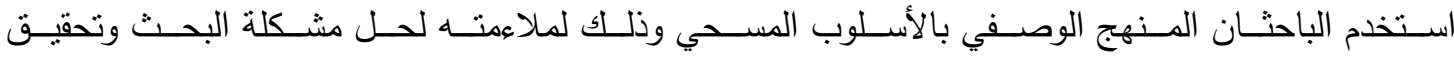

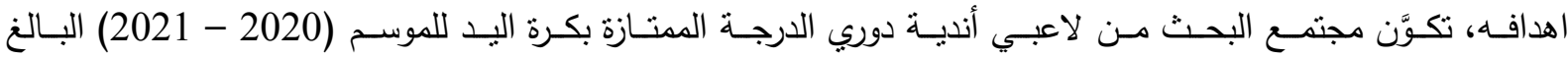

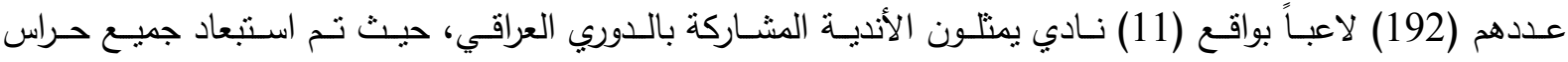

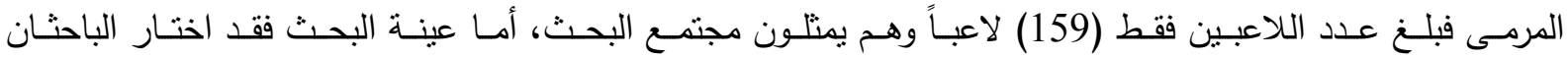

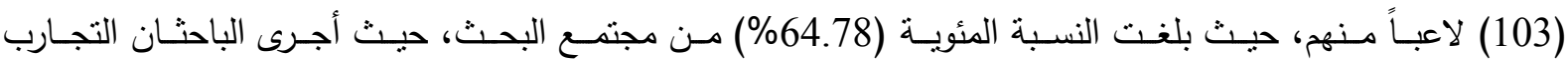

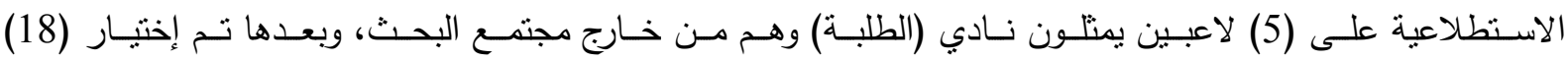




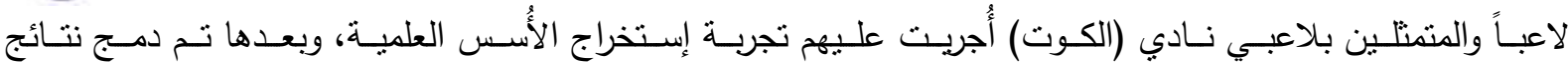

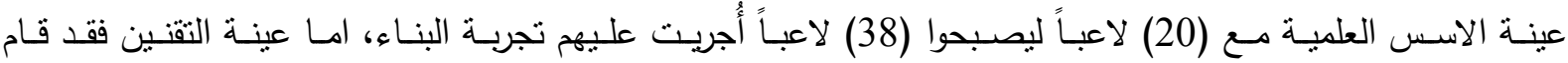
الباحـث بـإجراء الاختبـارات مـن خـلال تطبيقهـا علـى عينـة التقنـين والتهي تكونــت مـن (65) لاعبـاً، واسـتخراج الدرجات والمستويات المعيارية لها.

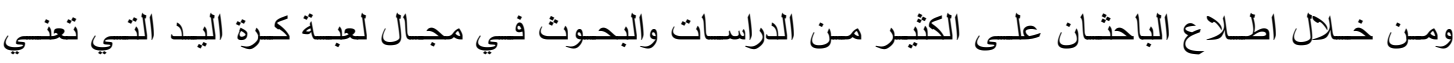

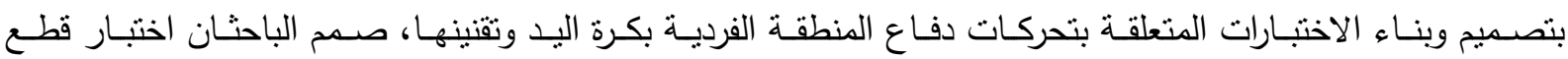
وتتنتيت الكرة بين اربعة لاعبي هجوم للاعبي اندية دوري الدرجة المثتازة بكرة اليد.

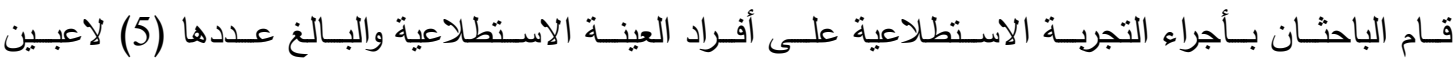

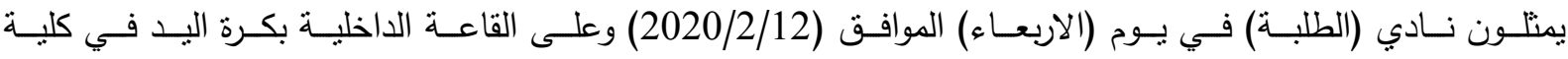

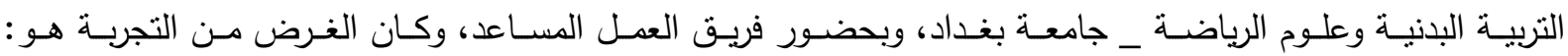

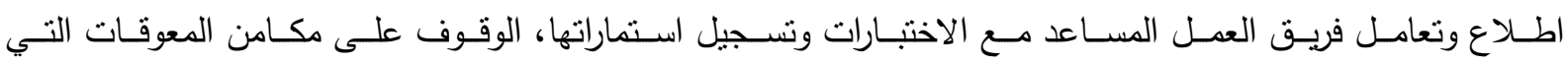

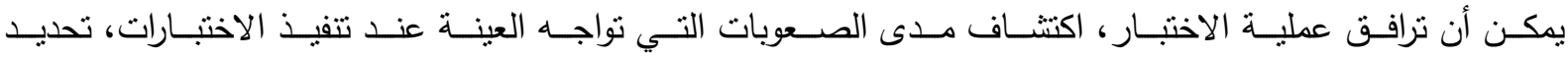

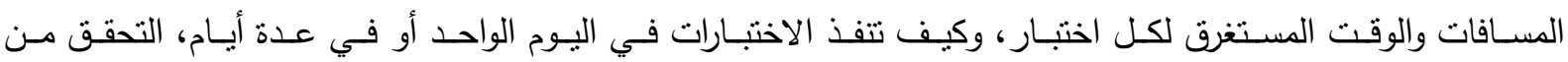
دقة الاجزة والادوات المستخدمة وسلامتها.

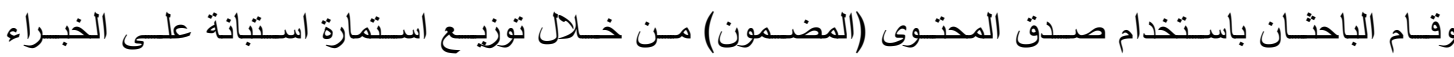

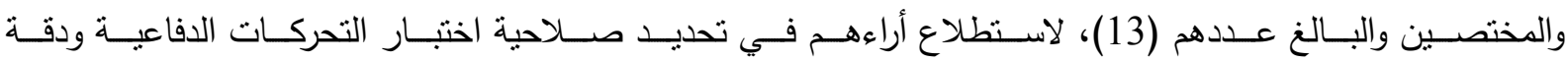
التصويب من القفز اماماً وقد اجمعوا على صلاحية الاختبار . وتـم إيجـاد الثبـات بطريقـة الاختبـار وإعـادة الاختبـار ، إذ تـم تطبيـق الاختبـارات علـى عينـة مكونـة مـن

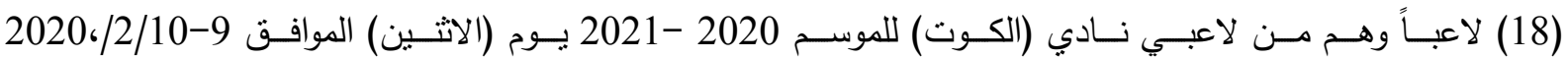
وتـم اعـادة الاختبـارات بعـد مـرور (6) ايـام تحـت نفس الظـروف وعلى نفس افـراد العينـة ، وتـم اسـتخراج معامـل

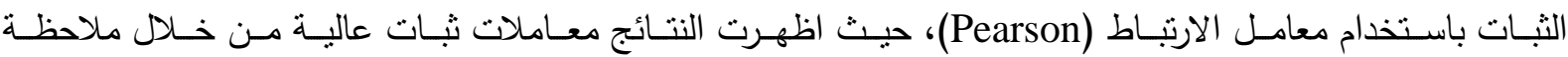
قيم الدلالة والتي هي اقل من (0.05) مما يشير الى معنوية الارتباط. الجدول (1) الصدق والثبات لاختبارات المركبة (بدنبي_ مهاري) المستخدمة في البحث

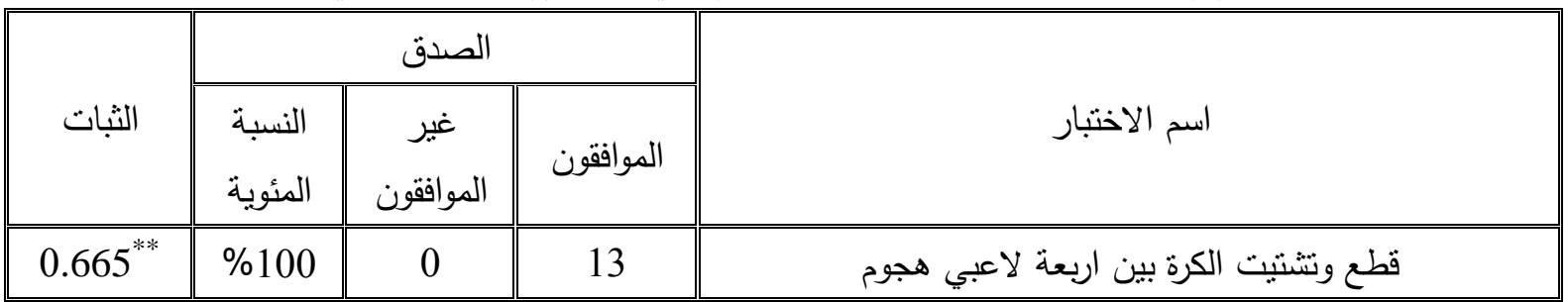

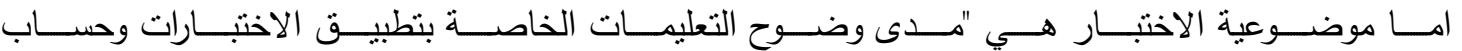

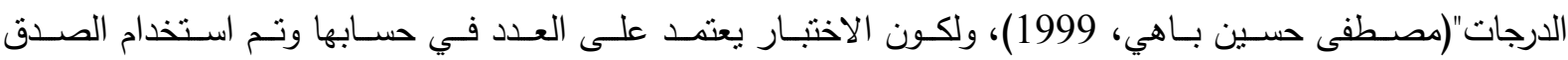
والثبات له فهو يعد ذات موضوعية عالية.

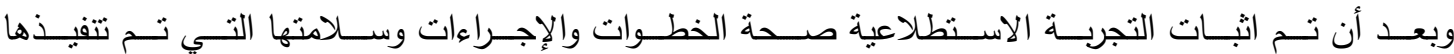
وتضـمينها الثـروط العلميـة للاختبـار فضــا عـن ملائمتهـا لعينـة البحـث والظـروف المحيطـة، قـام الباحثـان بتطبيـق

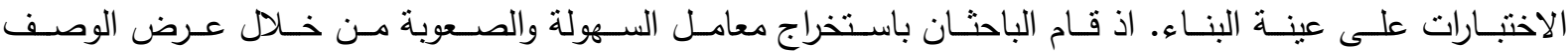

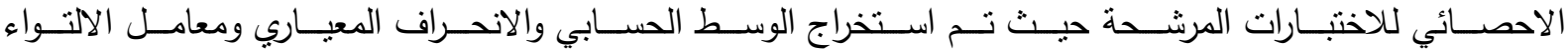

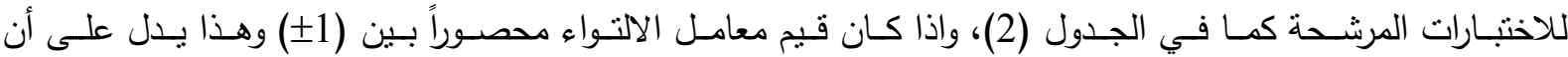
الاختبارات المستخدمة موزعة توزيعا طبيعياً وهذا يعني ان الاختبارات مناسبة. 
الجدول (2) قيم الاوساط الحسابية والانحرافات المعيارية ومعامل الالتواء للاختبارات

\begin{tabular}{|c|c|c|c|c|}
\hline الالنواء & الانحراف المعياري & الحسابي & وحدة القياس & اسم الاختبار \\
\hline 0.495 & 1.369 & 2.263 & عدد & قطع وتتشتيت الكرة بين اربعة لاعبي هجوم \\
\hline
\end{tabular}

وتم استخراج القدرة التمييزيــة اذ تم ترتيب الـدرجات الخـام الخاصـة بكل اختبـار ترتيبـاً تصـاعدياً مـن "أقـل

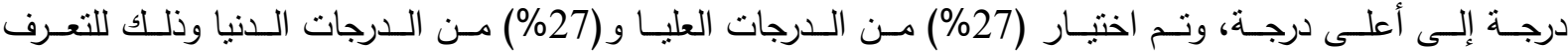

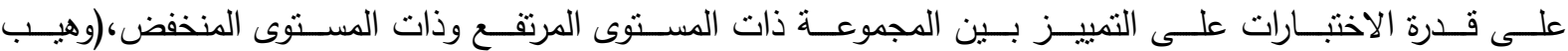
الكبيسي، 2010)، وعلى وفق ذلك تم استخدام اختبار (T) الإحصائي للعينات المتساوية غير المرتبطة.

الجدول (3) القدرة (القوة) التمييزية للاختبارات المركبة (بدني -مهاري) قبد الدراسة

\begin{tabular}{|c|c|c|c|c|c|c|c|}
\hline \multicolumn{2}{|c|}{ قيمة T } & \multicolumn{2}{|c|}{ المستوى المنخفض } & \multicolumn{2}{|c|}{ المستوى المرتفع } & \multirow{2}{*}{ القياس } & \multirow[b]{2}{*}{ اسم الاختبار } \\
\hline الديم & المحسوبة & $\varepsilon$ & س & $\varepsilon$ & س & & \\
\hline 0.000 & -9.153 & 0.483 & 0.700 & 0.994 & 3.900 & عدد & قطع وتشتيت الكرة بين اربعة \\
\hline
\end{tabular}

المواصفات النهائية لاختبار قطع وتثتيت الكرة بين أريعة لاعبي هجوم بكرة اليد:

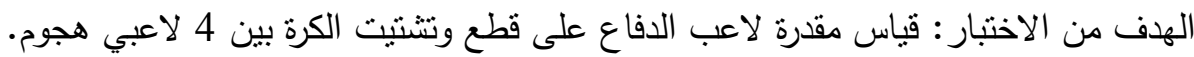

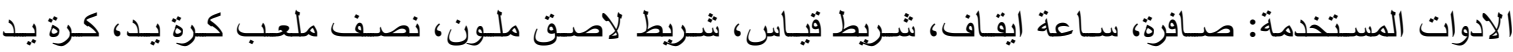
عدد (4)، لاعب هجوم عدد (4). وصف الاختبار وطريقة الاداء: يرسم مربع على ارض الملعب طول ضلعه (4 أمتار). يق كل لاعب هجوم على احد زوايا المربع، ويكون احدهم ممسكاً للكرة قبل انطلاق صافرة البدء.

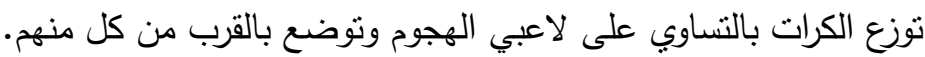
نرسم علامة دائرة في مركز المربع قطرها (1 منر)، يقف عليها لاعب الدفاع.

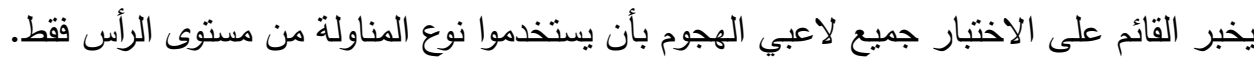

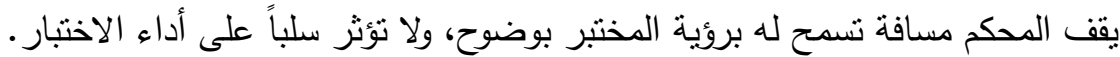

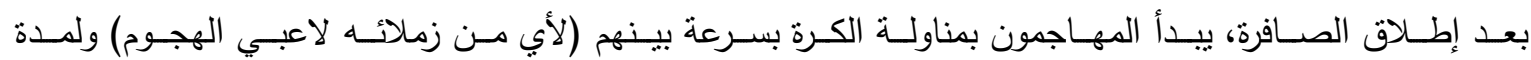
(30 ثانية)، ويبدأ المدافع تحركاته (بأنتهاز الفرصة المناسبة) لقطع وتشتيت الكرة.

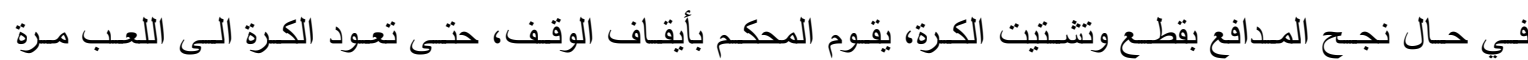
اخرى، ويستمر هكذا انتهاء الوقت المحدد.

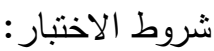

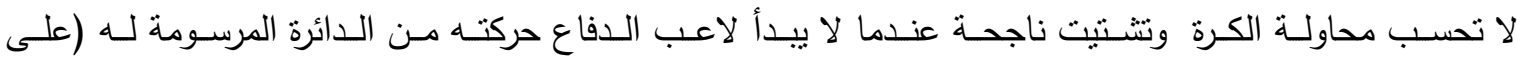
الاقل ان تكون احدى قدميه ملامسة للائرة).

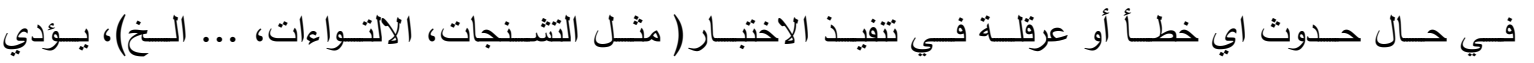
المختبر المحاولة التالية بعد التأكد منه عن جاهزيته لأداء الاختبار مرة ثانية. 


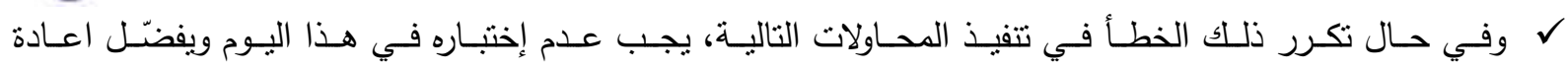

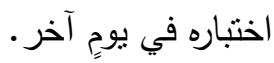

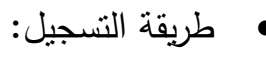
ل يمنح كل مختبر (محاولتان)، زمن كل محاولة (30 ثانية). ح ح حسب عدد الكرات المقطوعة والمشتتة لكل محاولة. ل تحتسب المحاولة الافضل.

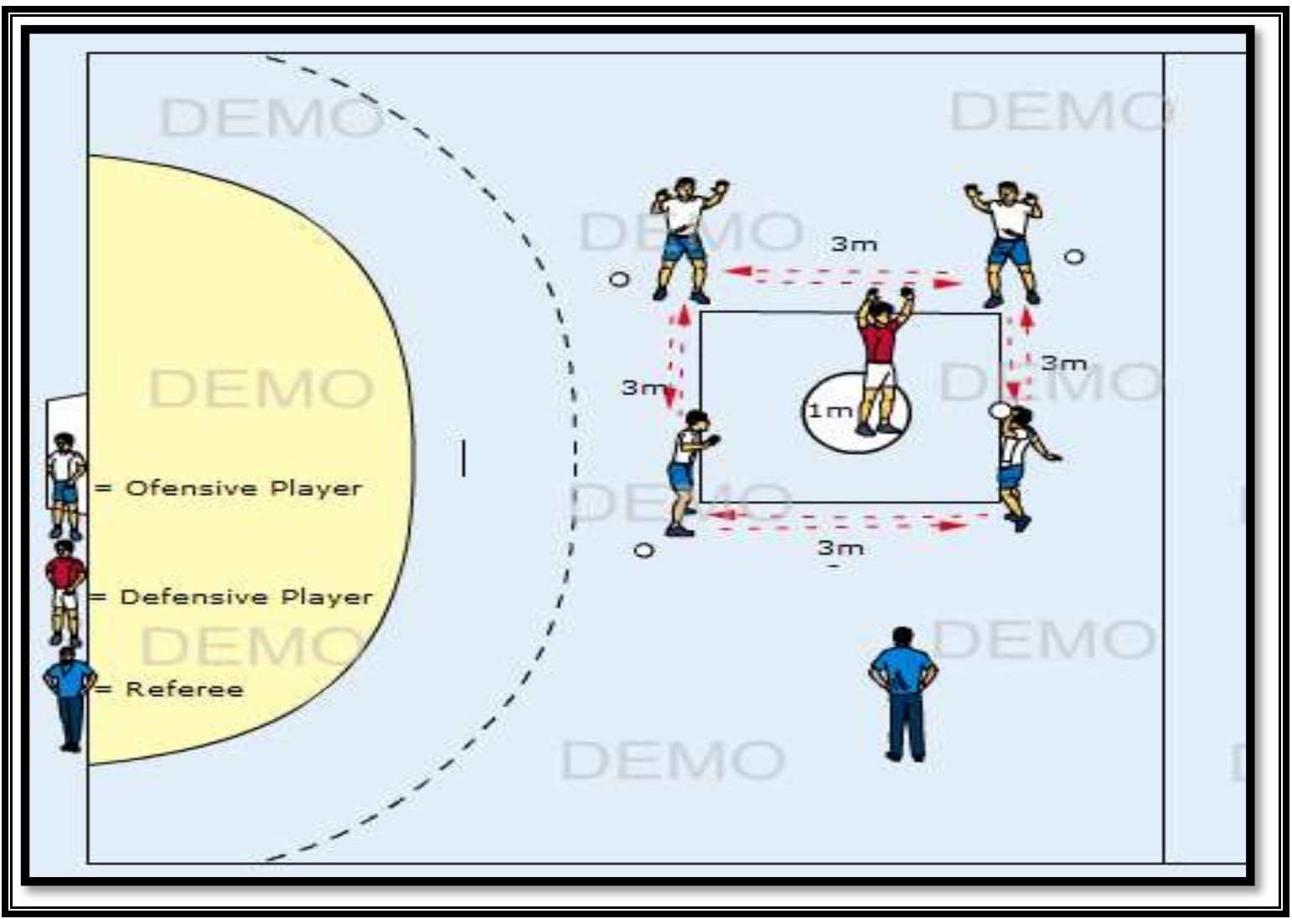

الثكل (1) إختبار قطع وتشتيت الكرة بين أربعة لاعبي هجوم بكرة اليد

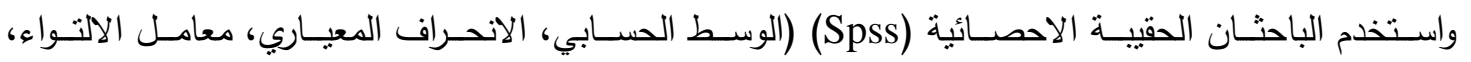

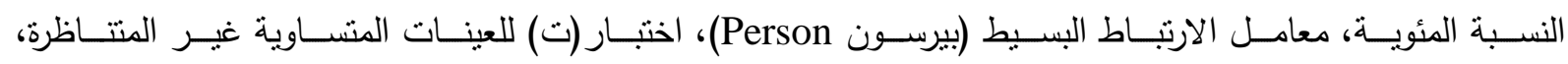
الدرجات المعيارية (الزائية والتائية).

النتائج:

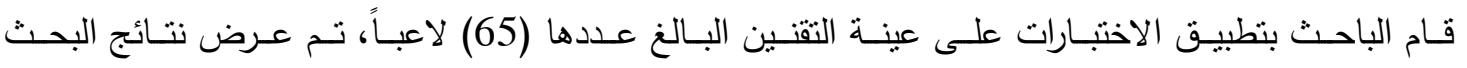

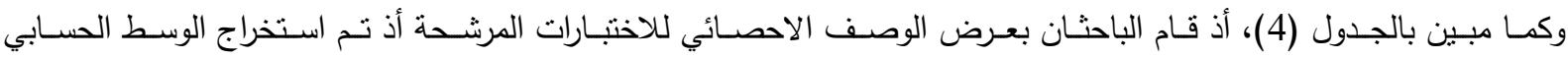

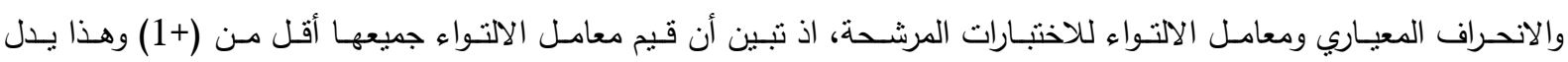

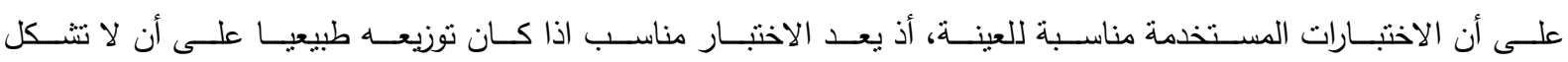
الاختبارات النواءً شديدا.(صلاح الدين محمد، 2000) 
الجدول (4) يبين قيم الاوساط الحسابية والانحرافات المعيارية ومعامل الالتواء لاختبار التحركات الدفاعية ودقة التصويب من الققز اماماً

\begin{tabular}{|c|c|c|c|c|}
\hline 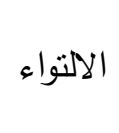 & الانحراف المعياري & الحسابي الوسط & وحدة القياس & اسم الاختبار \\
\hline 0.120 & 1.468 & 2.553 & عدد & قطع وتتنتيت الكرة بين اربعة لاعبي هجوم \\
\hline
\end{tabular}

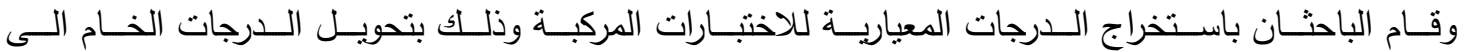

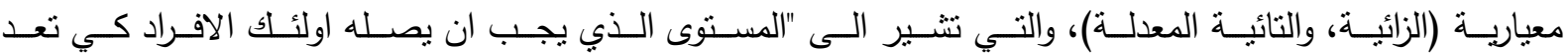
ابتهم مقبولة (صلاح الدين محمد، 2000)

إن المعـايير عبـارة عـن مجموعـة مـن الــرجات المشـتقة بطـرق إحصــائية معينــة مـن الـدرجات الخــام

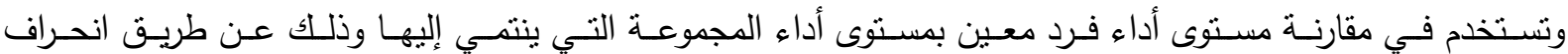

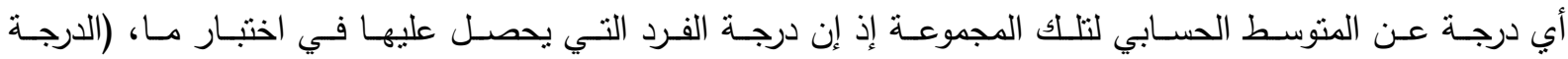

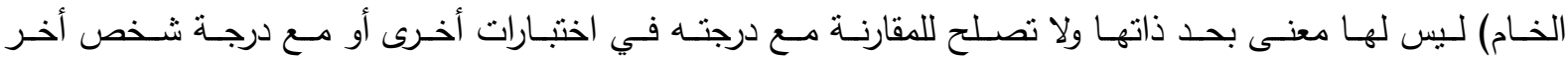

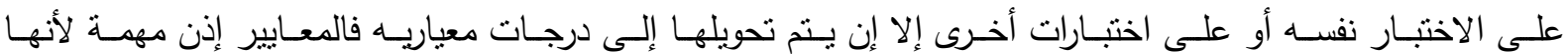
عبرت عن كيفية أداء الآخرين على الاختبار فتوفر بذلك أساسا للمقارنة.

(1998 ، Douglas N. Hasted \& Alan C. )

الجدول (5) الدرجات المعيارية (الزائية والتائية) لاختبار قطع وتثنتيت الكرة بين اربعة لاعبي هجوم

\begin{tabular}{|c|c|c|c|c|c|c|c|c|}
\hline الدرجة & الارجة & الدرجة الخام & الارجة & الارجة & الارجة & الارجة & الارجة & الارجة \\
\hline التائية & الزائية & د/ثا & التائية & الزائية & الخام د/ثا & التائية & الزائية & الخام د/ثا \\
\hline 53.04 & $\mathbf{0 . 3 0 3 7 7}$ & 3 & 46.23 & -0.37709 & 2 & 32.61 & -1.73879 & 0 \\
\hline 53.04 & $\mathbf{0 . 3 0 3 7 7}$ & 3 & 46.23 & $\begin{array}{l}-0.37709 \\
\end{array}$ & 2 & 32.61 & $\begin{array}{l}-1.73879 \\
\end{array}$ & $\mathbf{0}$ \\
\hline 53.04 & $\mathbf{0 . 3 0 3 7 7}$ & 3 & 46.23 & -0.37709 & 2 & 32.61 & -1.73879 & $\mathbf{0}$ \\
\hline 53.04 & $\mathbf{0 . 3 0 3 7 7}$ & 3 & 46.23 & -0.37709 & 2 & 32.61 & -1.73879 & $\mathbf{0}$ \\
\hline 53.04 & $\mathbf{0 . 3 0 3 7 7}$ & 3 & 46.23 & -0.37709 & 2 & 32.61 & -1.73879 & $\mathbf{0}$ \\
\hline $\mathbf{5 9 . 8 5}$ & $\begin{array}{l}0.98462 \\
\end{array}$ & 4 & 46.23 & $\begin{array}{l}-0.37709 \\
\end{array}$ & 2 & 39.42 & $\begin{array}{l}-1.05794 \\
\end{array}$ & 1 \\
\hline $\mathbf{5 9 . 8 5}$ & $\begin{array}{l}0.98462 \\
\end{array}$ & 4 & 46.23 & $\begin{array}{l}-0.37709 \\
\end{array}$ & 2 & 39.42 & $\begin{array}{l}-1.05794 \\
\end{array}$ & 1 \\
\hline 59.85 & 0.98462 & 4 & 46.23 & -0.37709 & 2 & 39.42 & -1.05794 & 1 \\
\hline $\mathbf{5 9 . 8 5}$ & $\begin{array}{l}0.98462 \\
\end{array}$ & 4 & $\begin{array}{l}53.04 \\
\end{array}$ & $\begin{array}{l}\mathbf{0 . 3 0 3 7 7} \\
\end{array}$ & 3 & 39.42 & $\begin{array}{l}-1.05794 \\
\end{array}$ & 1 \\
\hline $\mathbf{5 9 . 8 5}$ & $\begin{array}{l}0.98462 \\
\end{array}$ & 4 & 53.04 & $\begin{array}{l}0.30377 \\
\end{array}$ & 3 & 39.42 & -1.05794 & 1 \\
\hline $\mathbf{5 9 . 8 5}$ & $\begin{array}{c}0.98462 \\
\end{array}$ & 4 & 53.04 & $\begin{array}{c}\mathbf{0 . 3 0 3 7 7} \\
\end{array}$ & 3 & 39.42 & $\begin{array}{l}-1.05794 \\
\end{array}$ & 1 \\
\hline $\mathbf{5 9 . 8 5}$ & $\begin{array}{l}0.98462 \\
\end{array}$ & 4 & 53.04 & $\begin{array}{l}\mathbf{0 . 3 0 3 7 7} \\
\end{array}$ & 3 & 39.42 & $\begin{array}{l}-1.05794 \\
\end{array}$ & 1 \\
\hline $\mathbf{5 9 . 8 5}$ & $\begin{array}{l}0.98462 \\
\end{array}$ & 4 & 53.04 & $\begin{array}{l}0.30377 \\
\end{array}$ & 3 & 39.42 & $\begin{array}{l}-1.05794 \\
\end{array}$ & 1 \\
\hline$\overline{59.85}$ & $\begin{array}{l}0.98462 \\
\end{array}$ & 4 & $\begin{array}{l}53.04 \\
\end{array}$ & $\begin{array}{l}\mathbf{0 . 3 0 3 7 7} \\
\end{array}$ & 3 & 39.42 & $\begin{array}{l}-1.05794 \\
\end{array}$ & 1 \\
\hline 66.65 & 1.66547 & 5 & 53.04 & $\begin{array}{l}\mathbf{0 . 3 0 3 7 7} \\
\end{array}$ & 3 & 39.42 & -1.05794 & 1 \\
\hline 66.65 & 1.66547 & 5 & 53.04 & $\mathbf{0 . 3 0 3 7 7}$ & 3 & 39.42 & -1.05794 & 1 \\
\hline 66.65 & 1.66547 & 5 & 53.04 & $\mathbf{0 . 3 0 3 7 7}$ & 3 & 39.42 & -1.05794 & 1 \\
\hline 66.65 & $\mathbf{1 . 6 6 5 4 7}$ & 5 & 53.04 & $\mathbf{0 . 3 0 3 7 7}$ & 3 & 39.42 & -1.05794 & 1 \\
\hline 66.65 & $\begin{array}{l}1.66547 \\
\end{array}$ & 5 & 53.04 & $\begin{array}{l}0.30377 \\
\end{array}$ & 3 & 46.23 & $\begin{array}{l}-0.37709 \\
\end{array}$ & 2 \\
\hline 66.65 & 1.66547 & 5 & 53.04 & $\begin{array}{l}\mathbf{0 . 3 0 3 7 7} \\
\end{array}$ & 3 & 46.23 & $\begin{array}{l}-0.37709 \\
\end{array}$ & 2 \\
\hline 73.46 & 2.34633 & 6 & $\begin{array}{l}\mathbf{5 3 . 0 4} \\
\end{array}$ & $\mathbf{0 . 3 0 3 7 7}$ & 3 & 46.23 & $\begin{array}{l}-0.37709 \\
\end{array}$ & 2 \\
\hline & & & \begin{tabular}{l|l|}
$\mathbf{5 3 . 0 4}$ \\
\end{tabular} & $\overline{\mathbf{0 . 3 0 3 7 7}}$ & $\overline{3}$ & 446.23 & $\begin{array}{l}\mathbf{- 0 . 3 7 7 0 9} \\
\end{array}$ & 2 \\
\hline
\end{tabular}




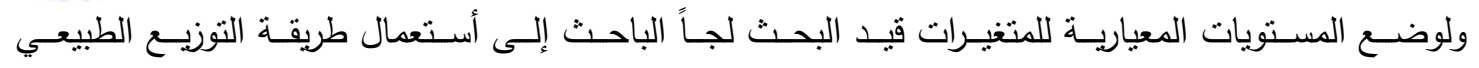

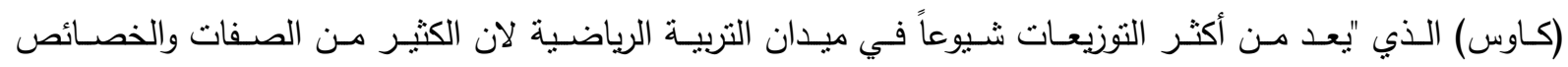

التي تقاس في هذا المجال يقترب توزيعها من المنحى الطبيعي" (عبدالحمديد و خيري، 1973) الشكل (2).

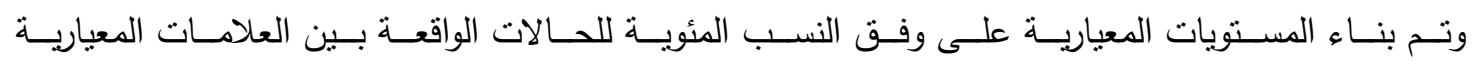

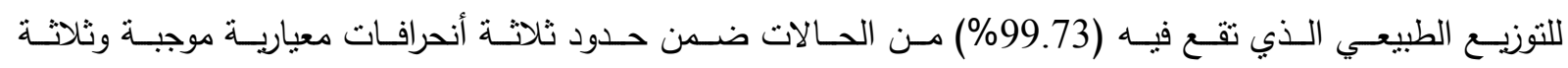

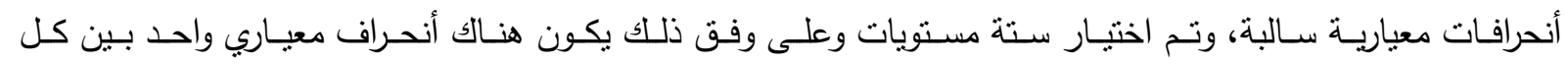

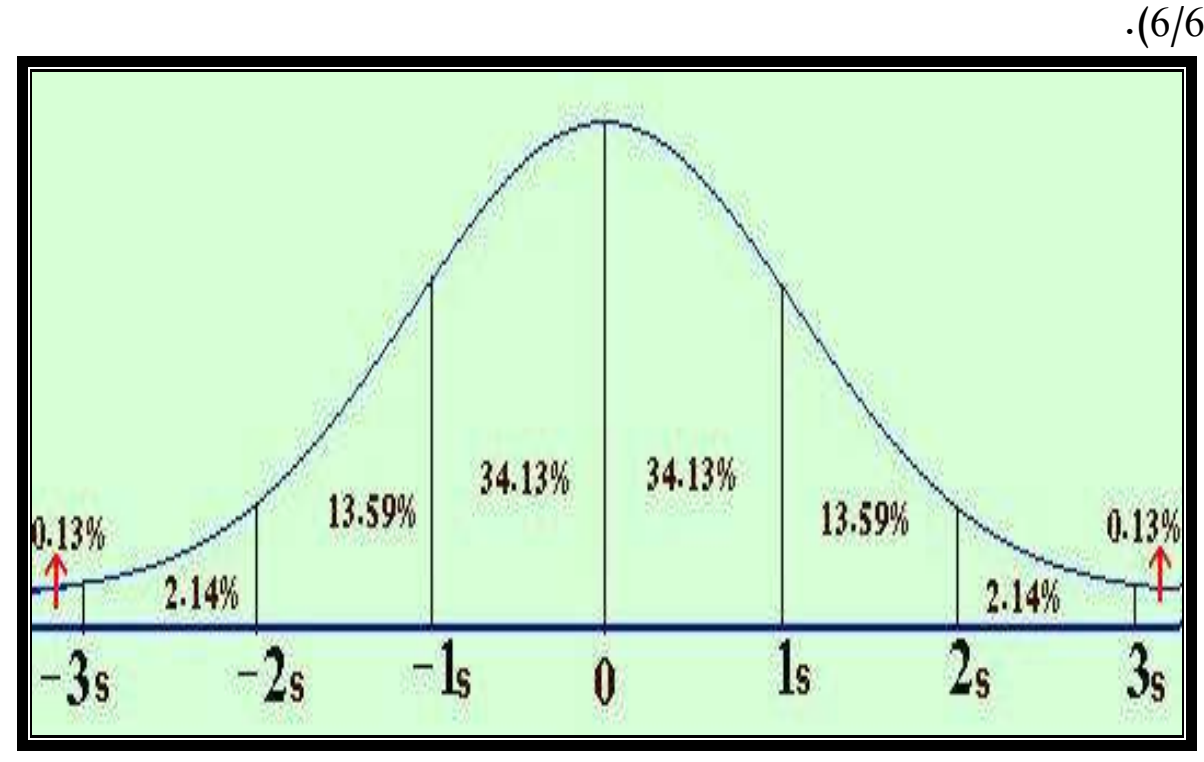

الثكل (2) يوضح منحنى النوزيع الطبيعي (كاوس)

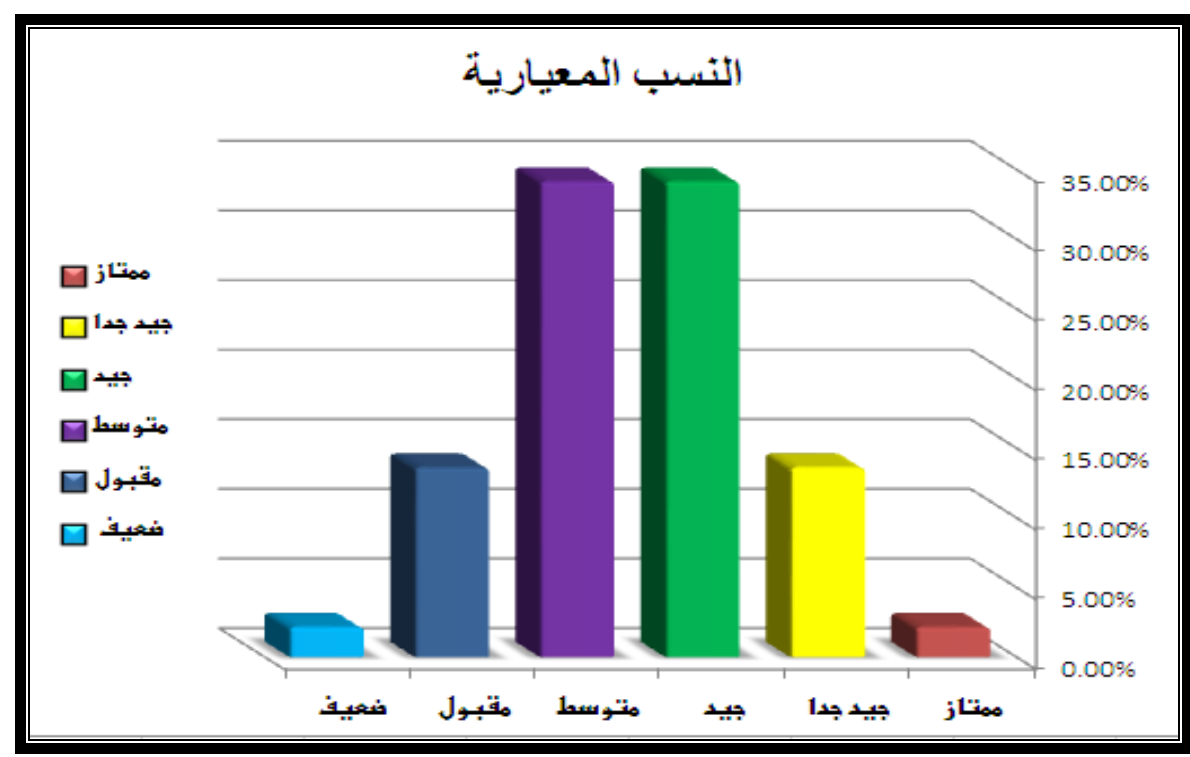

الثكل (3) يوضح المستويات والنسب المعيارية 
الجدول (6) ييين حدود المستويات المعيارية لاختبار قطع ونتنتيت الكرة بين اربعة لاعبي هجوم

\begin{tabular}{|c|c|}
\hline حدود المستويات & المستويات المعيارية \\
\hline $1-0$ & ضعيف \\
\hline $2.01-1.01$ & مقبول \\
\hline $3.02-2.02$ & متوسط \\
\hline $4.03-3.03$ & جيد \\
\hline $5.04-4.04$ & جيد جداً \\
\hline $6.05-5.05$ & متاز \\
\hline
\end{tabular}

مـن الجـدول السـابق الخـاص باختبـار قطـع ونتــتيت الكـرة بـين اربعـة لاعبـي هجـوم، أنحصـرت حـدود المستويات بين المستوى ضعيف البالغة (0 _ 1) وبين المستوى الممتاز البالغ (5.05 - 6.05).

الجدول (7) يبين حدود المستويات المعيارية ونسبها المئوية لاختبار قطع وتتشتيت الكرة بين اربعة لاعبي هجوم

\begin{tabular}{||c||c||c||c||c||c|c|}
\hline \multicolumn{7}{|c|}{ حدود المستويات } \\
\hline \hline
\end{tabular}

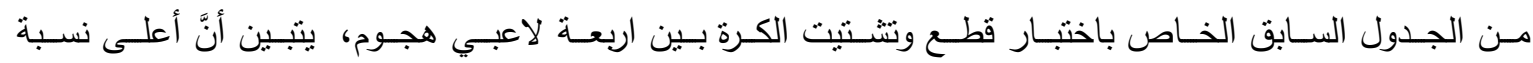

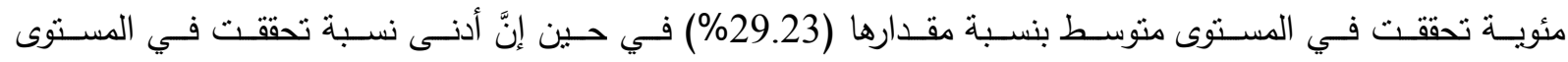

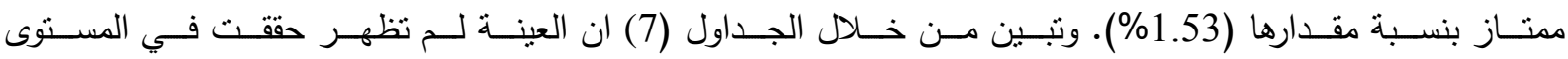

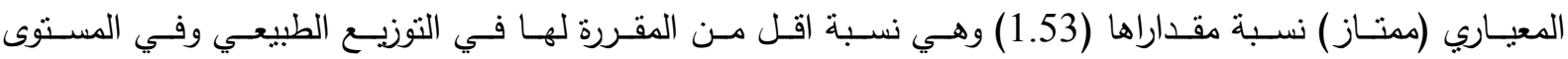

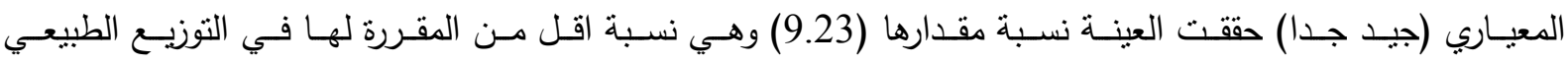
وفـي المسـتوى المعيـاري (جيـد) حققت العينـة نسـبة مقـدارها (13.84) وهـي نسـبة اقـل مـن المقـرة لهـا في التوزيـع

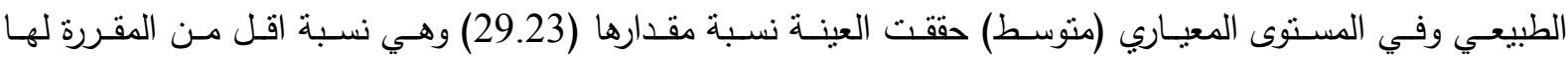

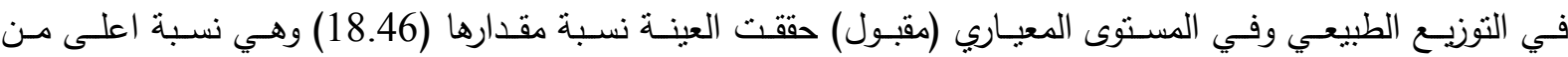

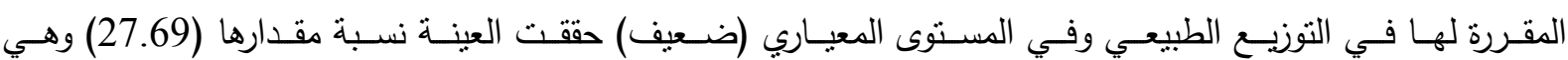
نسبة اعلى من المقررة لها في التوزيع الطبيعي. ويتبـين للباحـث مدــا ســق ان هنـاك اخـتلاف فـي النسـب المئويـة للمسـتويات المعياريـة التـي حققهـا اللاعبـون على وفق الاختبار قياسا بالمقرر لها في منحنى التوزيع الطبيعي.

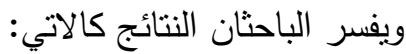

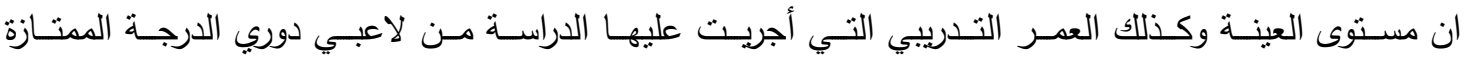

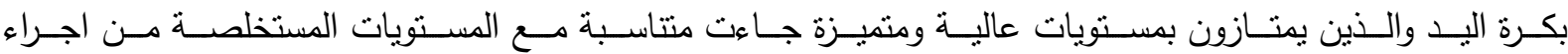
الاختبـارات عليهم اذ تمركزت النتائج بـين مسـتوى (جيد ضـعيف) و سـبب هـذا يعـود لعـدم انتظـام التـدريبات نسبياً

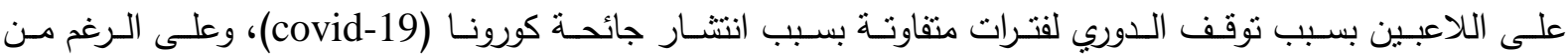


وجـود تفـاوت في هـذه المسـتويات وهـذا يعـود الـى مبـدا الفـروق الفرديـة وبالتـالي فــان تحقيـق العينـة نسـب اقـل فـي

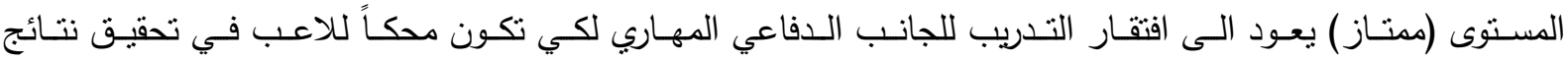

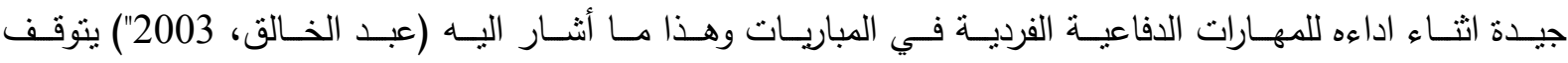
التحسن بالأداء المهاري على مدى الاهتمام وتطوير الجوانب البدنية والحركية المرتبطة بالمهارة.

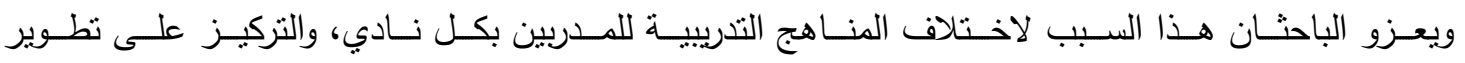

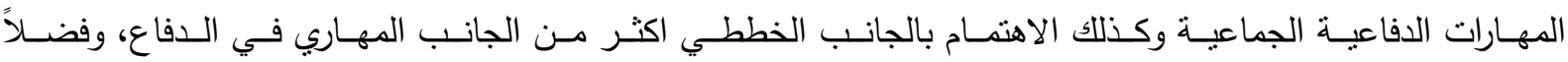
عن كثرة النوقفات في التدريبات لعدم معرفة استمرارية الدوري من عدمه.

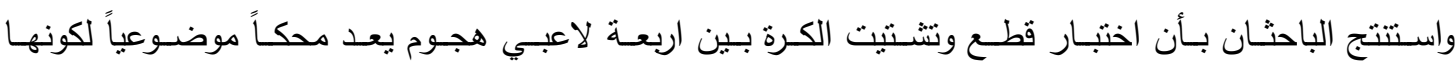

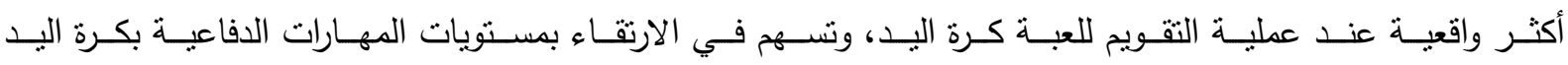

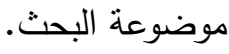

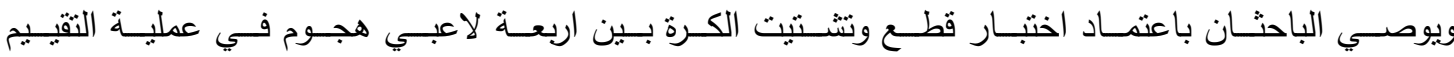

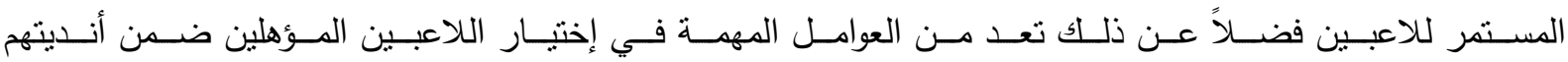
والمنتخـب الـوطني بكـرة اليـد، وبنـاء اختبـارات دفاعيـة اخـرى على فئسات عمريـة غيـر عينـة البحـث الحاليـة فضــلاً عن المهارات التي لم تبحث، وكذلك إلاهتمام بتدريب المهارات الدفاعية.

\section{المصــادر}

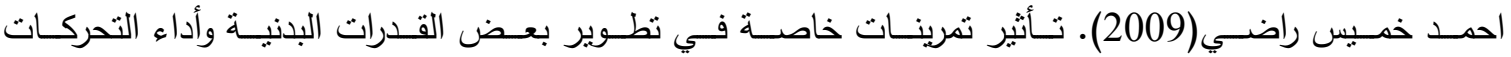

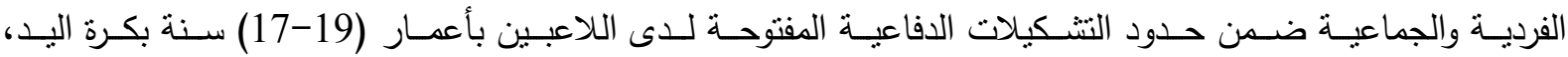
اطروحة دكتوراه، جامعة بغداد، كلية التربية البدنية وعلوم الرياضة. اميـرة حنـا مـرقص(2001). بنـاء وتقنـين مقيساس الاحتـراق النفسـي لـدى لاعبـي كـرة اليدا، (أطروحـة دكتـوراه، كلية التربية البدنية وعلوم الرياضة، جامعة بغداد)، صولفرو.

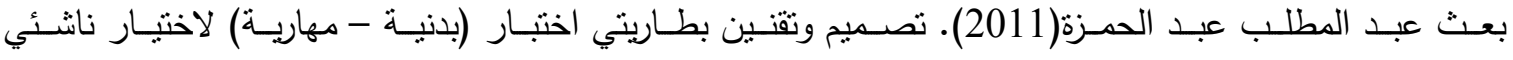
خماسي كرة القدم في بغداد بأعمار (14-16) سنة، رسالة ماجستير ، جامعة بغداد، كلية التربية الرياضية.

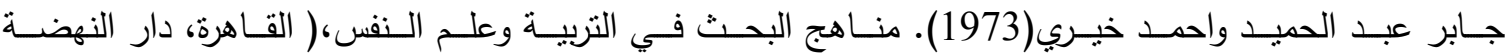
العربية)، ص301.

صــلاح الـدين محمــد عـلام (2000). تحليـل بيانــات البحـوث النفسـية والتزبويـة والاجتماعيـة، (القـاهرة، دار

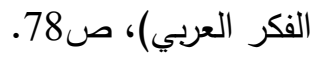

عصــام عبـــ الخــالق(2003). التــدريب الرياضــي_نظريــات نطبيـق، ط9.الأــكندرية، منشــأة المعــارف،

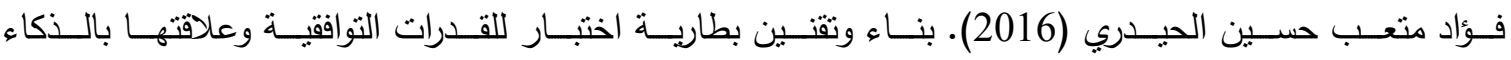

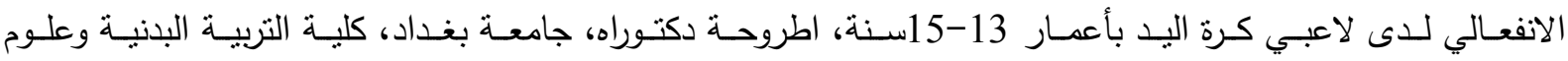
الرياضة.

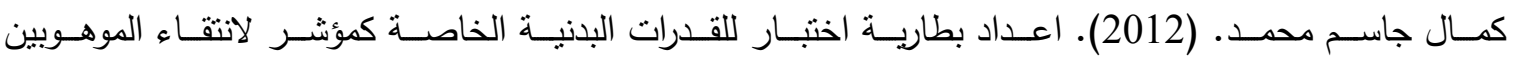
بكرة اليد في محافظة ديالى، مجلة علوم الرياضة.

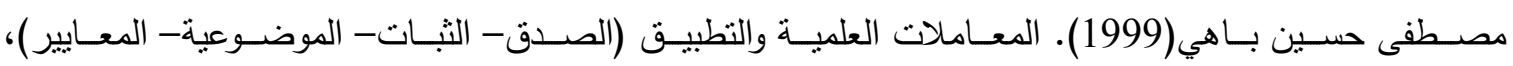

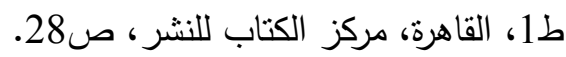




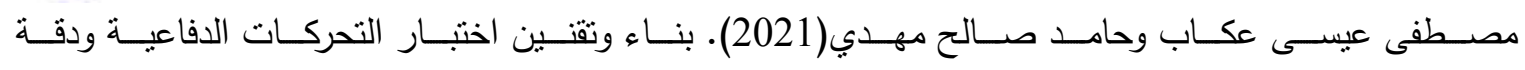

التصويب من القزز اماماً للاعبي كرة اليد بأعمار (15_17) سنة.

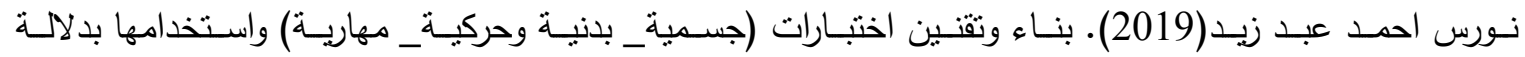

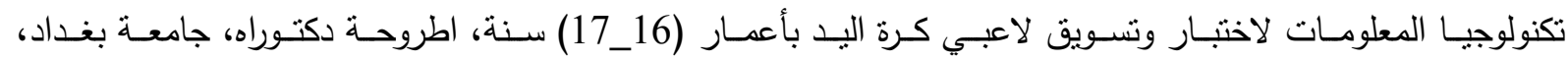
كلية التربية البدنية وعلوم الرياضة.

وجيـه محجـوب (وآخـرون)(2000). البحــث العلمـي ومناهجـه، (بغــاد، وزارة التعلـيم العـالي والبحــث العلمـي)،

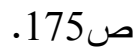

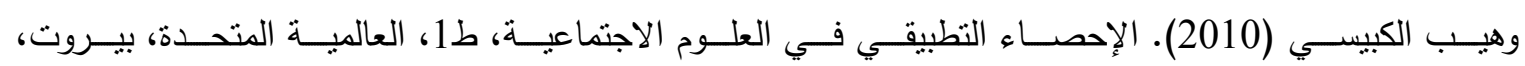
لبنان، ص276.

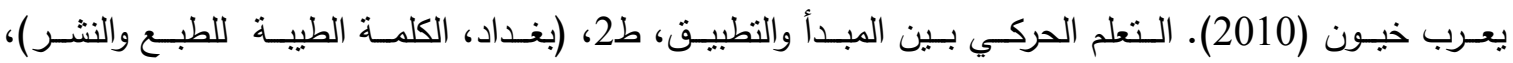

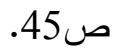

Douglas N. Hasted \& Alan C. (1998). Measurement and evaluation in Physical Education and Science ،Allyn \&Bacon, USA, p73 